\title{
AWARENESS DURING GENERAL ANAESTHESIA: PRELIMINARY OBSERVATIONS
}

\author{
J. W. R. MCINTYRE, F.F.A.R.C.S."
}

DRUGs with the ability to produce general anaesthesia are commonly used to cause a state in which the patient is oblivious of self and environment. Employed in smaller quantities, sometimes reinforced by suggestion, it is possible to produce a state in which the patient is analgesic and able to tolerate an abnormal situation while retaining some knowledge of his surroundings, and an ability to communicate in a selected manner with persons in his vicinity. Trichlorethylene has been used in this way; Artusio described a technique of ether analgesia, ${ }^{1,2}$ while for many years nitrous oxide with air or oxygen was a valuable adjunct to out-patient surgery and midwifery. There are numerous historical references to drugs administered orally or by injection to induce a similar state, and the contemporary use of neurolepts and analgesics was preceded by other pharmacological techniques such as the induction of "twilight sleep" with morphine and scopolamine, or "synergistic analgesia" with magnesium sulphate and morphine. ${ }^{3}$

In the early days of inhalational anaesthesia gratitude for analgesia probably outweighed any surprise that total oblivion was not always achieved. After some years a clear distinction between anaesthesia producing total unawarenessgeneral anaesthesia-and other artificially induced states-primarily associated with analgesia-was made, and one technique or the other was deliberately employed. It appears that not until the clinical advent of neuro-muscular blocking drugs with their prominent paralysing action was serious thought given to the patient's being inadvertently awake when general anaesthesia had been anticipated, and particular interest was taken in the possibility that the patient might be aware of pain. As case reports of this actually happening are few, 4,5 this occurrence seems to have been very rare indeed. However, cautionary editorials were published, ${ }^{b-8}$ and evidence has since been presented that patients might be aware of pain at a time of stimulus, but that this experience might only be recalled under special circumstances in the postoperative period. ${ }^{9-11}$. It has also been suggested that the site of surgery might be related to the character of such dreams as might occur under anaesthesia ${ }^{12}$ and psychiatric observations on surgical patients during recovery from anaesthesia have been made. ${ }^{13}$

Associated with concern regarding a patient's pain perception was interest in their ability to hear, understand, and perhaps remember what might be said in their presence during surgery. Reported cases are few, ${ }^{14-16}$ but many anaesthetists can quote personal knowledge of an incident of this kind, and it is possible that other occurrences of this nature have passed unnoticed. The wide-spread use of nitrous oxide stimulated investigation of this particular facet of the drug's activity, ${ }^{17-21}$ and the evidence presented did not exclude the possibility that,

-Department of Anaesthesia, University of Alberta Hospital, Edmonton, Alberta. 
depending on the quantity used, biological variation, technical factors, or differing stimuli, the subject might have some understanding of what was heard. However, the likelihood of there being memories of this period was very small, and the use of ancillary drugs made it even more an unlikely event in clinical anaesthetic practice.

Though a patient is unable to consciously recall a certain event, it is possible that auditory stimuli could at the time be interpreted as a stressful situation, and the physiological responses might or might not be observed depending on their character. Thus it is of interest not only whether the patient can remember, but whether he can interpret the stimulus at the time of its application. This consideration is particularly relevant in the use of small quantities of inhalational agents, narcolepts, analgesics, and combinations of these agents that can be substituted for nitrous oxide. Although the specificity of clinical activity of available analgesics does not approach that of the relaxants, the possibility nevertheless seems to exist that the patient might be unresponsive to the painful stimulus of surgery, but be responsive to an auditory stimulus. The observation has been made that patients rendered partially analgesic with a combination of fentanyl and droperidol can respond to auditory commands regarding respiratory depression. In view of the varying pharmacological techniques becoming available, further investigation of hearing under anaesthesia seemed pertinent at the present time.

The first study to be reported here concerned the possibility of remembering in the postoperative period facts heard during anaesthesia. A simple story using significant words ${ }^{22}$ was tape recorded and played through insulated head-phones in a normal speaking range, peaking at 55 decibels. The wording was as follows: "I am going to tell you a story. Listen carefully, because I want you to remember everything I say to you. Mary Thomas of South Edmonton, employed as a cleaning woman at a building on Jasper Avenue, reported at the Police Station that she had been robbed of $\$ 15$ outside the church. Her husband had been angry with her, and she hoped the police would help her find the money." It was repeated four times, twice by a female voice and twice by a male voice in a clearly enunciated, moderately emotional tone. By using a message of this nature, it was believed possible to identify temporally any memories or dreams, thus avoiding the difficulty experienced by Rosen ${ }^{23}$ who used commonly heard sounds; at the same time it would provide something for the patient to remember, instead of an interpretation of operating room sounds as relied on by Hutchison. ${ }^{24}$ On the second or third day postoperatively, an interview concerning all facets of the operative and anaesthetic experience was performed by an observer unfamiliar with the details of the story.

The subjects were all young females, twelve undergoing Caesarean section, and five, abdominal gynecological procedures. The anaesthetic technique involved premedication with $0.6 \mathrm{mg}$. atropine, induction with thiopentone 1.0 to $2.0 \mathrm{mg}$. per pound body weight, and maintenance with nitrous oxide and oxygen 3.5 to 1.5 litres per minute into a semi-closed circle absorber system. Relaxants were used when indicated, and ventilation varied from 50 to 150 per cent in excess of their Radford Nomogram value. The time at which the tape was played varied 
for each patient, and was between 10 and 90 minutes after induction of anaesthesia.

The results of the postoperative interviews indicated that the patients had no recollection of their operating room experience, nor any dreams or impressions that could be related to their auditory stimulus. This is probably due to the pharmacological effect of nitrous oxide, and the lack of significance of the information provided to this particular group of women. It is not considered possible to draw any conclusions beyond the facts presented.

The object of the second study was to ascertain whether the patient would respond to a spoken command, or exhibit signs of arousal produced by isolated paired significant words during a time of approximately uniform surgical stimulus to which there was no respiratory or cardiovascular response. A tape recording was made of one hour duration, and at ten-minute intervals a thrice-repeated request was made for the eyes to be opened. At a time which varied within each ten-minute period, one minute was occupied by ten paired, emotionally significant words, randomly spaced within that minute. Thus the tape could be started at any ten-minute period and the time of request to open the eyes would be known to the observer, but the arousal stimulus would not. A similar tape was constructed in which nonsense words were used, and both were played at a normal speaking voice level peaking at 55 decibels. The words used were: red $\times 2$, white $\times 2$, church $\times 2$, mother $\times 2$, green $\times 2$, boy $\times 2$, father $\times 2$, bed $\times 2$, good $\times$ 2 , girl $\times 2$. The criteria for arousal were definite movements of head, hand, or arm. When the series of cases had been completed, the time of arousal was compared with the time at which the auditory stimulus had occurred.

Twenty subjects were studied, ten receiving meaningful and ten receiving meaningless stimuli during orthopedic and plastic procedures, or during the termination of abdominal surgery. The anaesthetic technique involved premedication with atropine $0.6 \mathrm{mg}$., induction with thiopentone 1.0 to $2.0 \mathrm{mg}$. per pound of body weight, and 4 litres per minute of 0.5 to 1.0 per cent methoxyflurane and oxygen from a Pentec vaporizer into a semi-closed circle absorber system for 15 minutes, and maintenance with 4 litres per minute of 0.12 to 0.3 per cent methoxyflurane. A combination of fentanyl and droperidol in proportions of 1:20 was administered intermittently during induction and maintenance. At a time when the surgical stimulus had stabilized and the patient was breathing spontaneously with stable blood pressure and pulse, the auditory stimulus was applied. This was 30 to 120 minutes from induction of anaesthesia.

No response occurred in any of the patients to whom the meaningless stimulus was applied. Of the other ten patients, the eyes of nine failed to open, and the eyes of one opened briefly and closed spontaneously. In the latter patient the head also moved at the time the word sequence was applied, as was the case in two other patients. Arm movements occurred in two patients, one of them already mentioned. Thus four out of ten patients receiving the meaningful stimulus moved at the time of its application.

It has been observed that the analgesic state produced by approximately 0.39 per cent methoxyflurane differs from that produced by diethyl ether or nitrous oxide, and stronger auditory stimuli are needed for arousal. ${ }^{25}$ 
Using the anaesthetic technique described here almost all of the twenty patients would open their eyes at the termination of surgery, and it is possible that had the recorded request been louder and more persistent more patients would have done so during surgery. The difference in the response to the paired words compared with the requests may be because the former were delivered over a period of 60 seconds, and the latter during only 20 seconds. Alternatively, a discriminatory response could have occurred, and the meaningful or emotional content of a word or words within the ten word sequence could have produced the response observed. This latter explanation does not necessarily apply to the consistent lack of response to the nonsense words; for that, a varying degree of drug-induced central depression or variation in surgical stimulus may have been responsible. However the observations reported are submitted as evidence that discrimination of auditory stimuli may occur while the patient is tolerating certain surgical stimuli in the state of drug-induced depression described, and when no deliberate pre- or peroperative attempts at suggestion have been made.

\section{SUMMARY}

Reference has been made to experimental work and clinical reports of discrimination between sounds while patients are under general anaesthesia, and of recall in the postoperative period. A report is made of seventeen patients under nitrous oxide oxygen anaesthesia who failed to recall a story told to them during surgery. Paired words applied to ten patients under methoxyflurane fentanyl droperidol anaesthesia were associated with motor signs of arousal in four of them.

\section{RÉSUMÉ}

Nous faisons allusion à un travail expérimental et à des rapports cliniques sur le discernement de certains sons, sous anesthésie générale, et la possibilité de s'en souvenir au cours de la période post opératoire. Nous rapportons l'histoire de 17 malades soumis à une anesthésie au protoxyde d'azote et à l'oxygène qui nont pas pu se souvenir d'une histoire qu'on leur avait racontée au cours de la chirurgie. Chez dix malades sous anesthésie au méthoxyflurane, fantanyl et droperidol on a dit des mots appairés et, chez quatre d'entre eux, cela a été fait au moment où ils manifestaient des signes moteurs de réveil.

\section{REFERENCES}

1. Antusro, J. F: Diethylether Analgesia: A Detailed Description of the First Stage of Ether Anesthesia in Man. J. Pharmacol. \& Exper. Therap. 111: 343 (1954).

2. - Ether Analgesia during Major Surgery. J.A.M.A. 157: 33 (1955).

3. Gwaxmaney, J. T. Anesthesia. 2nd ed., London: Churchill (1925).

4. Wanterbotrom, E. H. Insufficient Anaesthesia. Brit. M. J. I: 247 (1950).

5. Grafr, J. D. \& Paml.rps, C. P. Consciousness and Pain during Apparent Surgical Anaesthesia. J.A.M.A. 170: 2069 (1959).

6. Consciousness during Surgical Operations. Editorial, Brit. M. J. 2810 (1959).

7. Auwd, E. E. Awareness during Surgery. Lancet. 2: 1394 (1961).

8. Cовв, S. Muscle Relaxants and Pain Perception. Anesthesiology. 22: 314 (1961).

9. ChEEer, D. B. Areas of Research into Psychosomatic Aspects of Surgical Tragedies Now Open through the use of Hypnosis and Ideomotor Questioning. West. J. Surg. 70: 137 (1962). 
10. - - Surgical Memory and Reaction to Careless Conversation. Am. J. Clin. Hypn. 6: 237 (1964).

11. - Further Evidence of Persistence of Hearing under Chemo Anaesthesia: Detailed Case Report. Am. J. Clin. Hypn. 7: 55 (1965).

12. Polrock, G. H. \& Muscrn, H. L. Dreams during Surgical Procedures. Psychoanalyt. Quart. 31 : 175 (1962).

13. Winkelstent, Crartes et al. Psychiatric Observations on Surgical Patients in Recovery Room-Pilot Study. New York J. Med. 65: 865 (1965).

14. Mushin, W. Analgesics as Supplements during Anaesthesia. Proc. Roy. Soc. Med. 44: 840 (1951).

15. Alment, E. A. Consciousness during Surgical Operation. Brit. M. J. 2: 1258 (1959).

16. PARKhouse, J. Awareness during Surgery. Postgrad. Med. 36: 674 (1960).

17. Steinberg, Hannah. Selective Effects of Anaesthetic Drugs on Cognitive Behaviour. Quart. J. Exper. Psychol. 6: 170 (1954).

18. PARKHouse, J. et al. Nitrous Oxide Analgesia in Relation to Mental Performance. J. Pharmacol. \& Exper. Therap. 128: 44 (1960).

19. Robson, J. G. et al. The Effect of Inhaling Dilute Nitrous Oxide upon Memory and Time Estimation. Canad. Anaesth. Soc. J. 7: 399 (1960).

20. Bunns, B. D. \& Robson, J. G. The Effects of Nitrous Oxide upon Sensory Thresholds. Canad. Anaesth. Soc. J. 7: 411 (1960).

21. HENRIE, J. R. et al. Alteration of Human Consciousness by Nitrous Oxide as Assessed by Electroencephalography and Psychological Tests. Anesthesiology. 22: 247 (1961).

22. WECHSLER, D. Standardized Memory Scale for Clinical Use. J. Psychol. 19: 87 (1945).

23. Rosen, Jorgen. Hearing Tests During Anaesthesia with Nitrous Oxide and Relaxants. Acta anaesth. scandinav. 3: 1 (1959).

24. Hutchinson, R. Awareness during Surgery. A Study of its Incidence. Brit. J. Anaesth. 33: 463 (1961).

25. Lambie, R. D. The Analgesia of Methoxyflurane. Canad. Anaesth. Soc. J. 10: 469 (1963). 